\title{
Dew Formation, Eddy-Correlation Latent Heat Fluxes, and the Surface Energy Imbalance at Cabauw During Stable Conditions
}

\author{
Stephan R. de Roode · Fred C. Bosveld • Petra S. Kroon
}

Received: 13 March 2009 / Accepted: 9 February 2010 / Published online: 7 March 2010

(C) The Author(s) 2010. This article is published with open access at Springerlink.com

\begin{abstract}
Observations collected between 2000 and 2008 at the Cabauw meteorological measurement platform in the Netherlands were conditionally sampled to select nights with stably stratified atmospheric conditions, clear skies and weak horizontal wind speeds $\left(<3 \mathrm{~m} \mathrm{~s}^{-1}\right)$. For these conditions the eddy-correlation latent heat fluxes are found to be negligibly small, while the conditionally sampled surface energy balance exhibits a maximum residual. However, inspection of the specific humidities for these conditions reveals systematic drying trends that are a maximum at the lowest measurement level above the surface. These drying trends occur for any prevailing wind direction. Latent heat fluxes are calculated from the humidity budget equation and from a Penman-Monteith dewfall model, with the results suggesting that during clear, stable nights the observed latent heat fluxes as obtained from the eddy-correlation technique are erroneously small.
\end{abstract}

Keywords Cabauw $\cdot$ Dew $\cdot$ Surface energy balance $\cdot$ Stable boundary layers . Turbulent fluxes

\section{Introduction}

The Cabauw meteorological measurement platform in the Netherlands is specifically designed for boundary-layer research (Van Ulden and Wieringa 1996) and the Cabauw data series are frequently used to validate modelling results. For example, Cabauw data were used

S. R. de Roode ( $\square)$

Clouds, Climate and Air Quality, Department of Multi-Scale Physics, Delft University of Technology, P.O. Box 5046, 2600 GA Delft, The Netherlands

e-mail: S.R.deRoode@tudelft.nl

S. R. de Roode · F. C. Bosveld

Koninklijk Nederlands Meteorologisch Instituut, De Bilt, The Netherlands

P. S. Kroon

Energy Research Centre of the Netherlands (ECN), Petten, The Netherlands 
for the design of a modelling intercomparison case for the stable boundary layer (Holtslag 2006).

At Cabauw, the surface energy balance (SEB) components are measured on a routine basis. The SEB is determined by the net shortwave and net longwave radiative fluxes, $S W_{\text {net }}$ and $L W_{\text {net }}$, respectively, the soil heat flux $G_{0}$, and the turbulent fluxes of sensible and latent heat, $H$ and $L_{v} E$, respectively, viz.

$$
-G_{0}=S W_{n e t}+L W_{n e t}+H+L_{v} E,
$$

where $L_{v}=2.5 \times 10^{6} \mathrm{~J} \mathrm{~kg}^{-1}$ is the latent heat of vaporization. Note that positive values of energy fluxes in the atmosphere correspond to upward fluxes. It proves to be very difficult to close the SEB from field observations for a variety of reasons, e.g. Foken and Oncley (1995), Culf et al. (2004) and Foken (2008), and the non-closure of the SEB can be quantified by the residual term,

$$
R e s=S W_{n e t}+L W_{n e t}+H+L_{v} E+G_{0} .
$$

For a very dry arid region with low relative humidities and small latent heat fluxes Heusinkveld et al. (2004) showed that it is possible to obtain good closure of the SEB. Also Jacobs et al. (2008) were able to close the energy budget for a grass land site in the Netherlands. Kroon (2003) investigated the SEB at Cabauw as a function of the mean total wind speed and found that during the night the residual was particularly large for weak mean horizontal wind speeds $\left(<3 \mathrm{~m} \mathrm{~s}^{-1}\right)$. It was also found that during very stable conditions the latent heat fluxes obtained with the eddy-correlation (EC) technique tended to become negligibly small.

In general the ground water level at Cabauw is relatively high and the atmosphere rather moist. If the atmosphere is relatively moist, low wind speeds favour the formation of dew during stably stratified conditions (Holtslag and de Bruin 1988). Dewfall is frequently observed in the Netherlands (Jacobs et al. 2006), and results from a downward transport of water vapour from the atmosphere to the ground surface.

In this paper we summarize the findings from the study of Kroon (2003), and question whether the latent heat flux as observed with the EC method gives too low values during calm and stable nights. To this end we use the humidity budget equation (Garratt 1994) and observed vertical profiles of humidity tendencies to diagnose the latent heat flux. These results will be compared to the latent heat fluxes obtained with the EC method, and with dewfall results from the Wageningen meteorological observatory reported by Jacobs et al. (2006).

\section{Experimental Set-up and Data Selection}

\subsection{The Cabauw Tower Experimental Site}

The Cabauw tower is $213 \mathrm{~m}$ high and is specifically designed for meteorological research and establishing relations between the state of the atmospheric boundary layer (ABL), land surface conditions and the general weather situation in all seasons (Van Ulden and Wieringa 1996).

The Cabauw mast is located in the western part of the Netherlands $\left(51.97^{\circ} \mathrm{N}, 4.927^{\circ} \mathrm{E}\right)$ in a polder $0.7 \mathrm{~m}$ below average sea level. The North Sea is more than $50 \mathrm{~km}$ away to the west-north-west. The nearby region is agricultural, and surface elevation changes are at most a few metres over $20 \mathrm{~km}$. Near the mast the terrain is open pasture for at least $400 \mathrm{~m}$ in all directions, and in the west-south-west direction for $2 \mathrm{~km}$. Farther away, the landscape is 


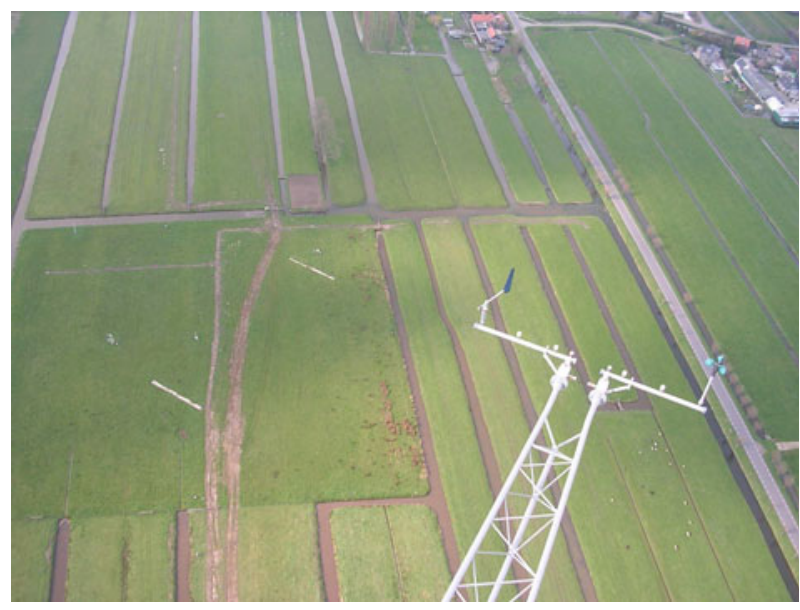

Fig. 1 Photograph of the surface area surrounding the Cabauw tower (courtesy Adriaan Schuitmaker). Note the frequent presence of straight ditches. The Cabauw surface area is representative for a large part of the Netherlands

generally very open in the western sector, while the distant eastern sector is rather rough (windbreaks, orchards, low houses). The distant northern and southern sectors are mixed landscapes, much pasture and some windbreaks. The local roughness length is about $0.03 \mathrm{~m}$, while the large-scale landscape roughness length is larger and about $0.15 \mathrm{~m}$, but depends slightly on the prevailing wind direction.

The soil consists of $0.6 \mathrm{~m}$ of river-clay, overlying a thick layer of peat. The water table is about $1 \mathrm{~m}$ below the surface, but can be higher during wet periods. The Cabauw region is also characterized by a regular pattern of numerous narrow, straight ditches having typical widths of a few metres (see Fig. 1). The ditches are separated by a typical horizontal distance on the order of $20-40 \mathrm{~m}$. In the vicinity of the tower the ditches are oriented in an approximate north-south direction, and at about $1 \mathrm{~km}$ south of the tower the river Lek flows in a westward direction.

\subsection{Instrumentation}

On the mast itself no undisturbed measurements can be made below $20 \mathrm{~m}$. Auxiliary 20-m masts are installed to the south-east and the north-west at a sufficient distance from the mast foot building. South of the mast is a well-kept observation field for micrometeorological observations, including soil heat flux, soil temperatures and various radiation measurements.

Wind speed is measured with cup-anemometer vane combinations and provisions are made to avoid flow interference due to mast obstruction. Temperature is measured with KNMI Pt500 elements in unventilated KNMI temperature huts, and relative humidity is measured with Väisälä HMP243 heated sensors in a separate unventilated hut. All these observations are collected at measurements heights of 200, 140, 80, 40, 20 and $10 \mathrm{~m}$. Temperature and humidity are also measured at 2-m height. Shortwave incoming radiation is measured with a Kipp and Zonen CM11 pyranometer, and longwave upward radiation is measured with an Eppley pyrgeometer. The surface soil heat flux is derived from soil heat-flux plates at 0.05 and $0.10-\mathrm{m}$ depth and soil temperatures at zero and 0.02-m depth. The method to derive surface 
soil heat-flux from these soil observations is described in De Bruin and Holtslag (1982) and takes into account the heat storage change between the sensors and the soil surface.

Turbulent sensible and latent heat fluxes are derived from a Kaijo-Denki sonic anemometer with probe type TR60-A and an infrared $\mathrm{H}_{2} \mathrm{O} / \mathrm{CO}_{2}$ open path sensor (Kohsiek 2000) at a measurement height of $5 \mathrm{~m}$. After 13 September 2006 a Gill R3 sonic anemometer/thermometer was used in conjunction with a Licor $7500 \mathrm{H}_{2} \mathrm{O} / \mathrm{CO}_{2}$ open path sensor at a lower measurement height of $3 \mathrm{~m}$. The open path sensor is positioned just behind the sonic anemometer probe and the combination is automatically turned into the wind each second hour. Turbulent observations are sampled at a rate of $10 \mathrm{~Hz}$. Fluxes were calculated on a 10-min time basis using the eddy-correlation technique, e.g. the latent heat flux

$$
L_{v} E_{E C}=\bar{\rho}_{a i r} L_{v} \frac{\sum_{i=1}^{N_{t}}\left(w_{i}-\bar{w}\right)\left(q_{i}-\bar{q}\right)}{N_{t}}
$$

where $\bar{\rho}_{\text {air }}$ is the mean density of air, $N_{t}$ is the number of measurements, and an overbar indicates the temporal mean of a variable. For example, for the vertical velocity $w$,

$$
\bar{w}=\frac{\sum_{i=1}^{N} w_{i}}{N}
$$

and likewise for the specific humidity $q$. Low frequency contributions beyond this time scale were parameterized on the basis of standard spectra given by Kaimal et al. (1972), though these corrections are small for stable conditions. High frequency loss occurs due to sensor path averaging and separation between the sonic anemometer and the water vapour sensor, with typical separation distances of $0.2 \mathrm{~m}$. The effect of very stable conditions can be considerable. Kroon et al. (2009) show that spectra of vertical wind speed under very stable conditions at Cabauw still have a well-defined inertial sub range, suggesting that high frequency flux loss can be estimated on the basis of spectra given by Kaimal et al. (1972). For stable conditions this may amount to $6 \%$. No corrections were performed since the exact magnitude is not well known and would not change the conclusions.

Density corrections on the humidity fluctuations were performed following Webb et al. (1980). Obstruction around the turbulence equipment causes a tilt of streamlines at the measuring volume of a few degrees, and the tilts were estimated from high wind speed cases over a period of typically a year. The main effect of this tilt is a cross-talk of horizontal wind fluctuations into the vertical wind sensor. These corrections are small for scalar quantities.

Plots of time series of all processed data were visually inspected to check for malfunctioning of the instruments. Most notably periods with dew formation on the turbulence sensors were easily recognized and removed from the dataset. A significant amount of periods remained when dewfall was anticipated and the instruments functioned appropriately.

Temperature and humidity sensors are regularly exchanged and calibrated at the KNMI laboratory. Temperature measurements in unventilated huts can become inaccurate under low wind conditions with high solar irradiation. At night longwave radiative cooling and dew formation may lead to underestimation of the temperature. The relative humidity sensors have limited absolute accuracy but have no specific problem with respect to stability over time periods of a day or less. This means that the current measurement set-up is not suitable for estimating fluxes from vertical differences, but is appropriate for investigating the rate of change in the vertical column.

To substantiate the claim that the current measurement set-up can be used to estimate the time rate of change of humidity in the vertical column we also analysed observations from an older Cabauw dataset (1986-1996) as described by Beljaars and Bosveld (1997). In that period psychrometers were used to obtain temperature and humidity (the sensors were $\mathrm{Cu} / \mathrm{Co}$ 
thermocouples). The psychrometers were strongly ventilated and double shielded. Accuracy of the wet-bulb and dry-bulb temperatures is a few $0.01^{\circ} \mathrm{C}$. Inspection of the sensors was done by visualising time series, which enabled the detection of wetting of the dry-bulb sensor due to rain or fog and drying of the wet-bulb sensor due to problems in the water supply. These conditions were flagged in the database and excluded from the analysis.

The surface temperature $T_{s}$ is derived from the measured upward longwave radiation according to the Stefan-Boltzmann law for blackbody radiation. From $T_{s}$ the saturation specific humidity $q_{s 0}$, with $q$ the specific humidity and the subscripts ' $s$ ' and ' 0 ' denoting its saturated and surface values respectively, is derived from the saturation mixing ratio $r_{s}=q_{s} /\left(1-q_{s}\right)$, and

$$
r_{s}=\frac{R_{d}}{R_{v}} \frac{e_{s}}{\left(p-e_{s}\right)}
$$

Here $p$ denotes the pressure, $R_{d}=287.06 \mathrm{~J} \mathrm{~kg}^{-1} \mathrm{~K}^{-1}$ and $R_{v}=461.5 \mathrm{~J} \mathrm{~kg}^{-1} \mathrm{~K}^{-1}$ are the gas constants for dry air and water vapour, respectively. The quantity $e_{s}$ indicates the saturation water vapour pressure, which is a function of the temperature $T$ in kelvin (Stull 1988),

$$
e_{s}=610.78 \exp \left(\frac{17.2694(T-273.16)}{T-35.86}\right) \text {. }
$$

During dewfall conditions the specific humidity $q$ at the surface equals the saturated value. Except for the results presented in Table 4, which presents results from wet-bulb temperature observations collected between 1986 and 1996, the data analysis is based on observations that were obtained in the period from 16 August 2000 to 17 November 2008.

\section{The Nighttime Surface Energy Balance}

Figure 2 shows the SEB components during nighttime as a function of the mean horizontal wind speed at $10-\mathrm{m}$ height. It is clear that the residual in the surface energy balance is maximum for low mean wind speeds and becomes smaller for increasing wind speed (Kroon 2003). For high wind speeds there is a significant evaporation from the surface. By contrast, for low wind speeds the mean values of the sensible and latent heat fluxes obtained with the EC method, $H_{E C}$ and $L_{v} E_{E C}$, respectively, become very small.

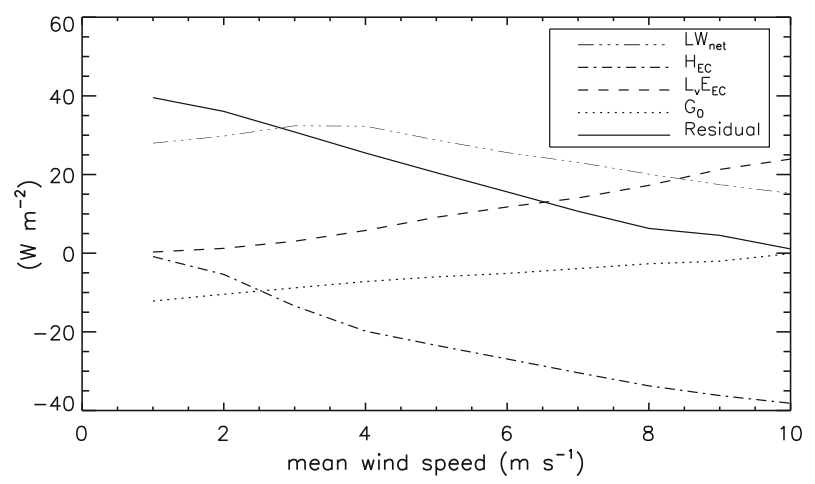

Fig. 2 The nighttime surface energy balance components as a function of the mean horizontal wind speed at the Cabauw site. The data were collected during a 8-year period from 2000 to 2008 
Figure 3 shows an example of humidities at different heights during a night with a stable stratification and a mean horizontal wind speed that gradually decreases. In the lower $40 \mathrm{~m}$ the observed atmospheric humidities gradually become smaller with time. During the time interval indicated by the two vertical lines, the results suggest that these humidity trends tend to follow the decrease in saturation specific humidity at the ground surface. For this period a small negative value for the EC latent heat flux is found, $L_{v} E_{E C}=-3.1 \mathrm{~W} \mathrm{~m}^{-2}$. The bulk Richardson number $R i_{B}$ gives a measure of the vertical stability,

$$
R i_{B} \equiv \frac{g}{\overline{\theta_{v}}} \frac{\Delta z \Delta \overline{\theta_{v}}}{(\Delta \bar{u})^{2}+(\Delta \bar{v})^{2}}
$$

where $\Delta z$ represents the height between two adjacent measurement levels. The virtual potential temperature was calculated from $\theta_{v}=\theta(1+0.61 q)$, with $\theta$ the potential temperature. To determine the vertical gradient of $\theta_{v}$ between the surface and $10 \mathrm{~m}$ height the surface temperature and humidity were used, where the latter was assumed to be at its saturation value. Very small vertical gradients in the horizontal wind speeds explain the rather large values for $R i_{B}$, which imply a very stable stratification. The small local wind maxima are indicative of low-level jets (LLJs). According to Baas et al. (2009) many LLJs at Cabauw originate from an inertial oscillation, which develops after sunset in a layer decoupled from the surface by a stable stratification. It is found that LLJs occur on about $20 \%$ of the nights, are typically situated between 140 and $260 \mathrm{~m}$ above ground level, and have a speed of about 6 to $10 \mathrm{~m} \mathrm{~s}^{-1}$. Development of a substantial LLJ is most likely to occur for moderate geostrophic forcing and a high radiative cooling.

\subsection{Conditional Sampling of Stable Conditions}

The very small values of the latent heat fluxes, the large residual in the SEB, and the fact that a drying trend near the ground is frequently observed during nighttime conditions with low wind speeds calls for a critical assessment of the surface humidity fluxes. To this end data were conditionally sampled according to the criteria presented in Table 1 . The radiation criteria were applied to select nighttime conditions with clear skies, and the vertical gradient of $\theta_{v}$ between the surface and 10-m height was used to select stably stratified conditions. The surface humidity was assumed to be at its saturation value. A maximum threshold value for the horizontal wind speed $u_{h}$ at 10-m height was applied to minimize the effects of both shear production of turbulence as well as horizontal advection of heat and moisture. Here $u_{h}=\left(\bar{u}^{2}+\bar{v}^{2}\right)^{1 / 2}$, and $(u, v, w)$ represents the wind velocity components in the north-south, east-west and vertical $(x, y, z)$ directions, respectively. The humidity tendency criterion applied at 2-m height avoids moistening by horizontal advection. All of the criteria select the conditions that favour dew formation. About $4.1 \%$ of the total number of data meet the selection criteria. Table 2 shows the monthly mean SEB components calculated from the conditionally sampled dataset. The quantity $N$ indicates the total number of $10-$ min data intervals satisfying the selection criteria according to Table 1 . The net longwave radiative cooling is the dominant term in the budget. The large value of the residual term indicates that the observed sensible, latent and soil heat fluxes do not balance the net longwave radiative loss. Note that for any month the monthly mean $L_{v} E_{E C}$ values are negligibly small.

In the absence of precipitation, the tendency of the specific humidity is governed by (overbars indicate 10- min mean values)

$$
\frac{\partial \bar{q}}{\partial t}=-\bar{u} \frac{\partial \bar{q}}{\partial x}-\bar{v} \frac{\partial \bar{q}}{\partial y}-\bar{w} \frac{\partial \bar{q}}{\partial z}-\frac{\partial \overline{u^{\prime} q^{\prime}}}{\partial x}-\frac{\partial \overline{v^{\prime} q^{\prime}}}{\partial y}-\frac{\partial \overline{w^{\prime} q^{\prime}}}{\partial z},
$$


5 Sep 2004
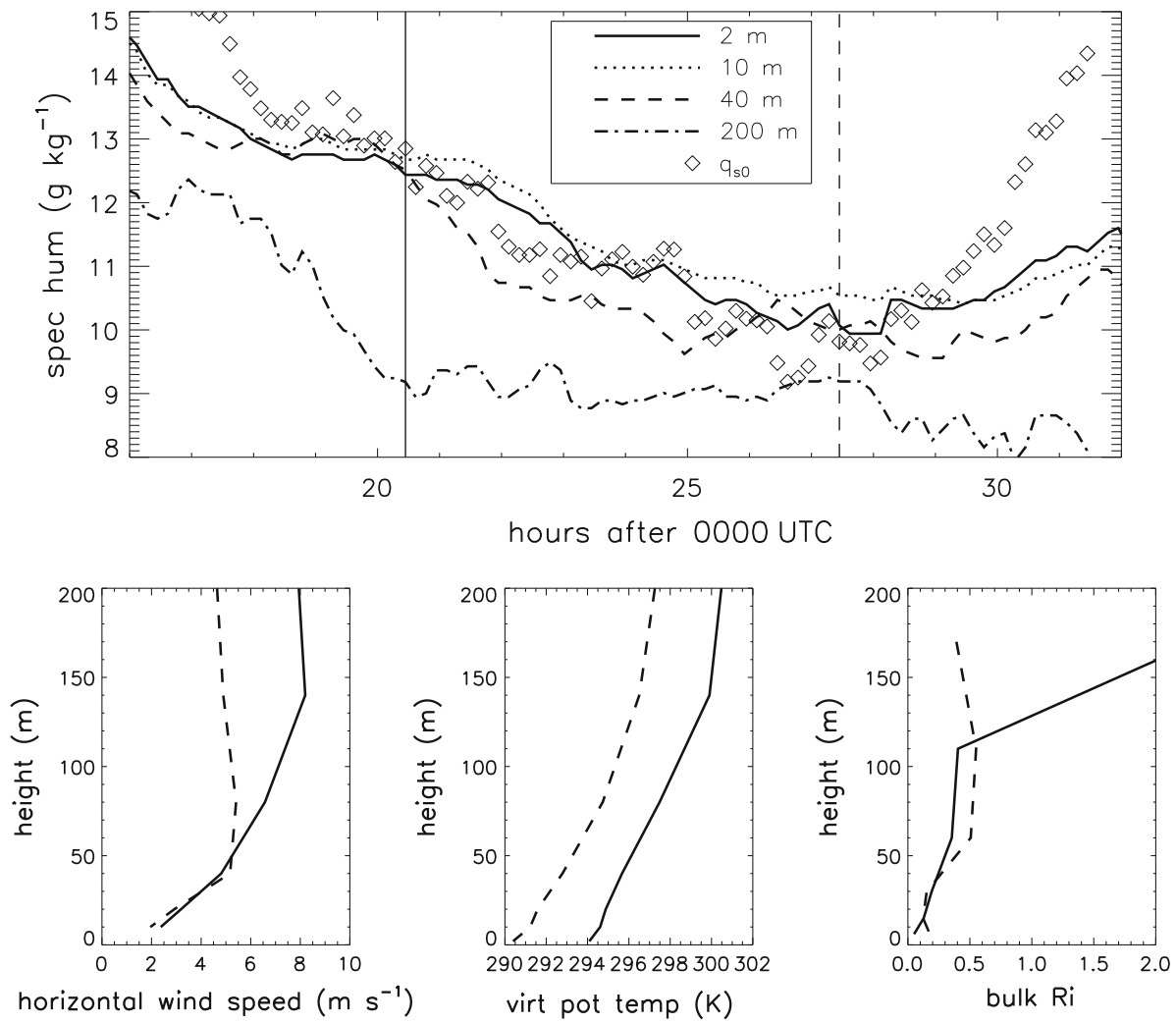

Fig. 3 Examples of humidity tendencies at different heights, and vertical profiles of the total wind speed, virtual potential temperature and bulk Richardson number during stable conditions with clear skies. The figure on top shows the saturation specific humidity at the ground surface $q_{s 0}$ (diamonds), and the specific humidities at $2 \mathrm{~m}$ (solid line), $10 \mathrm{~m}$ (dotted line), $40 \mathrm{~m}$ (dashed line) and $200 \mathrm{~m}$ (dash-dotted line). In the upper panel, the solid vertical line indicates the time at which the vertical profiles (solid lines) were observed, and likewise for the dashed line. The mean EC latent heat flux during period indicated by these two vertical lines is $L_{v} E_{E C}=-3.1 \mathrm{Wm}^{-2}$

Table 1 Summary of the conditional sampling criteria applied to the Cabauw dataset to select a nocturnal stable boundary layer with low wind speeds, clear skies and dew formation

\begin{tabular}{llll}
\hline & Selection & Criterion & Measurement height $(\mathrm{m})$ \\
\hline I. & Nighttime & $S W_{\text {net }}=0 \mathrm{~W} \mathrm{~m}^{-2}$ & 1 \\
II. & Clear sky & $L W_{\text {net }}>40 \mathrm{~W} \mathrm{~m}^{-2}$ & 1 \\
III. & Weak wind & $u_{h}<u_{\text {crit }}=3 \mathrm{~m} \mathrm{~s}^{-1}$ & 10 \\
IV. & Stable stratification & $\partial \overline{\theta_{v}} / \partial z>0 \mathrm{~K} \mathrm{~m}^{-1}$ & 0 and 10 \\
V. & Drying & $\partial \bar{q} / \partial t<0 \mathrm{~g} \mathrm{~kg}^{-1} \mathrm{~h}^{-1}$ & 2 \\
\hline
\end{tabular}

The vertical stratification is determined from the difference of $\theta_{v}$ between the ground and 10-m height

where the terms on the right-hand side of this equation indicate, respectively, the mean horizontal advection terms in the $x$ and $y$ directions, the mean vertical advection, the divergence of the horizontal turbulent flux in the $x$ and $y$ directions, and divergence of the vertical 
Table 2 Monthly mean surface energy balance for stable conditions calculated from Cabauw observations collected between 2000 and 2008

\begin{tabular}{lllllll}
\hline Month & $N$ & $H_{E C}\left(\mathrm{~W} \mathrm{~m}^{-2}\right)$ & $L_{v} E_{E C}\left(\mathrm{~W} \mathrm{~m}^{-2}\right)$ & $-G_{0}\left(\mathrm{~W} \mathrm{~m}^{-2}\right)$ & $L W_{\text {net }}\left(\mathrm{W} \mathrm{m}^{-2}\right)$ & $\operatorname{Res}\left(\mathrm{W} \mathrm{m}^{-2}\right)$ \\
\hline Jan & 1447 & $-6.9(0.91)$ & $-0.3(0.51)$ & $11.1(0.72)$ & 54.7 & 36.4 \\
Feb & 1411 & $-7.9(0.88)$ & $-0.4(0.61)$ & $11.4(0.72)$ & 53.6 & 34.0 \\
Mar & 1720 & $-6.6(0.88)$ & $0.1(0.63)$ & $13.5(0.74)$ & 52.5 & 32.5 \\
Apr & 1928 & $-7.0(0.95)$ & $0.9(0.72)$ & $14.6(0.63)$ & 50.7 & 30.0 \\
May & 1551 & $-9.7(0.91)$ & $2.3(0.74)$ & $15.6(0.65)$ & 49.1 & 26.1 \\
Jun & 1362 & $-8.6(0.94)$ & $1.2(0.79)$ & $17.5(0.64)$ & 48.2 & 23.2 \\
Jul & 1314 & $-9.1(0.94)$ & $1.4(0.72)$ & $15.0(0.61)$ & 47.0 & 24.2 \\
Aug & 2135 & $-8.7(0.84)$ & $0.6(0.62)$ & $14.1(0.69)$ & 47.3 & 25.1 \\
Sep & 2168 & $-8.9(0.87)$ & $-0.2(0.69)$ & $13.6(0.78)$ & 47.6 & 25.0 \\
Oct & 1895 & $-8.9(0.87)$ & $-1.3(0.65)$ & $10.7(0.62)$ & 48.7 & 27.9 \\
Nov & 1450 & $-6.4(0.80)$ & $-1.2(0.57)$ & $12.7(0.61)$ & 50.4 & 30.2 \\
Dec & 1825 & $-6.1(0.84)$ & $-1.1(0.48)$ & $13.8(0.78)$ & 52.9 & 31.8
\end{tabular}

The quantity $N$ indicates the total number of 10-min data intervals that satisfy the selection criteria according to Table 1 . The fraction of data that was used to compute the monthly mean values is indicated by the number within parentheses

turbulent humidity flux. If the mean advection and turbulent transport of water vapour are both very small, we expect that the humidity is close to a steady state. This, however, appears to be contrary to the findings presented in Table 3, which shows monthly averaged humidity tendencies for conditions that satisfy the sampling criteria according to Table 1. It is clear that at any height the monthly mean humidity tendencies are negative. For any month the mean drying trend is maximum at the lowest measurement height above the ground and becomes much smaller towards the top of the tower. The last column in the Table indicates the latent heat flux as diagnosed with aid of the humidity budget equation and the observed humidity tendencies along the tower. This is discussed in more detail in the next section.

To eliminate the possibility that the observed humidity tendencies result from instrumental malfunctioning we repeated the analyses using a different dataset. Until the year 1997 the specific humidity was calculated from the dry-bulb and wet-bulb temperatures (Beljaars and Bosveld 1997), and these data provide another, independent means to verify the observed mean drying trends found during stably stratified conditions. To select similar conditions, the conditional sampling routine was also applied to Cabauw data that were collected between 1986 and 1997. Note that these data were half-hourly averaged. Table 4 confirms the previous findings and shows net mean drying trends at all heights. Maximum values of the mean drying trend are found at a height of $0.6 \mathrm{~m}$ above the ground. However, the humidities obtained from the web-bulb temperatures show somewhat smaller tendencies in the lowest $10 \mathrm{~m}$ of the atmosphere as compared to the results from Table 3, and is perhaps due to the longer averaging times $(30 \mathrm{~min})$, which tend to smooth the tendencies.

\subsection{Humidity Tendency Statistics During Clear Nights with Low Wind Speeds}

To further investigate the humidity tendencies close to the ground the dataset was conditionally sampled using only criteria I, II and III from Table 1, which selects clear sky conditions with weak mean horizontal wind speeds. Since we wish to limit the possible effect of 
Table 3 Conditionally sampled monthly mean specific humidity tendencies for different measurement heights

\begin{tabular}{|c|c|c|c|c|c|c|c|c|c|}
\hline \multirow[t]{2}{*}{ Month } & \multirow{2}{*}{$\begin{array}{l}\partial q_{s 0} / \partial t \\
\left(\mathrm{~g} \mathrm{~kg}^{-1} \mathrm{~h}^{-1}\right) \\
\text { Surface }\end{array}$} & \multicolumn{7}{|c|}{$\begin{array}{l}\partial q / \partial t \\
\left(\mathrm{~g} \mathrm{~kg}^{-1} \mathrm{~h}^{-1}\right)\end{array}$} & \multirow{2}{*}{$\begin{array}{l}L_{v} E_{\text {budget }} \\
\left(\mathrm{W} \mathrm{m}^{-2}\right) \\
\text { Surface }\end{array}$} \\
\hline & & $2 \mathrm{~m}$ & $10 \mathrm{~m}$ & $20 \mathrm{~m}$ & $40 \mathrm{~m}$ & $80 \mathrm{~m}$ & $140 \mathrm{~m}$ & $200 \mathrm{~m}$ & \\
\hline Jan & -0.27 & -0.21 & -0.08 & -0.05 & -0.03 & -0.02 & -0.01 & -0.01 & -3.7 \\
\hline Feb & -0.29 & -0.23 & -0.09 & -0.06 & -0.04 & -0.03 & -0.02 & -0.03 & -3.9 \\
\hline Mar & -0.37 & -0.26 & -0.09 & -0.06 & -0.04 & -0.03 & -0.03 & -0.03 & -4.3 \\
\hline Apr & -0.43 & -0.29 & -0.11 & -0.07 & -0.05 & -0.03 & -0.03 & -0.02 & -5.4 \\
\hline May & -0.49 & -0.36 & -0.14 & -0.10 & -0.07 & -0.05 & -0.04 & -0.05 & -6.3 \\
\hline Jun & -0.56 & -0.36 & -0.13 & -0.09 & -0.05 & -0.02 & -0.03 & -0.03 & -5.0 \\
\hline Jul & -0.71 & -0.43 & -0.18 & -0.12 & -0.08 & -0.04 & -0.03 & -0.08 & -5.3 \\
\hline Aug & -0.69 & -0.44 & -0.18 & -0.13 & -0.08 & -0.04 & -0.08 & -0.07 & -7.8 \\
\hline Sep & -0.67 & -0.44 & -0.17 & -0.13 & -0.09 & -0.08 & -0.07 & -0.07 & -9.8 \\
\hline Oct & -0.61 & -0.38 & -0.17 & -0.14 & -0.11 & -0.09 & -0.07 & -0.08 & -9.9 \\
\hline Nov & -0.49 & -0.36 & -0.15 & -0.10 & -0.07 & -0.07 & -0.06 & -0.06 & -7.8 \\
\hline Dec & -0.29 & -0.26 & -0.10 & -0.07 & -0.05 & -0.04 & -0.05 & -0.04 & -5.4 \\
\hline
\end{tabular}

The Cabauw observations were collected between 2000 and 2008 and were conditionally sampled according to the selection criteria presented in Table 1 . The surface value indicates the tendency of the saturation specific humidity, which is computed from the radiative surface temperature. The column displaying $L_{v} E_{\text {budget }}$ gives the latent heat flux computed from the budget equation for the specific humidity (Eq. 12)

Table 4 Conditionally sampled monthly mean specific humidity tendencies for different measurement heights

\begin{tabular}{|c|c|c|c|c|c|c|c|c|c|c|}
\hline \multirow[t]{2}{*}{ Month } & \multirow{2}{*}{$\begin{array}{l}\partial q_{s 0} / \partial t \\
\left(\mathrm{~g} \mathrm{~kg}^{-1} \mathrm{~h}^{-1}\right)\end{array}$} & \multicolumn{8}{|c|}{$\begin{array}{l}\partial q / \partial t \\
\left(\mathrm{~g} \mathrm{~kg}^{-1} \mathrm{~h}^{-1}\right)\end{array}$} & \multirow{2}{*}{$\begin{array}{l}L_{v} E_{\text {budget }} \\
\left(\mathrm{W} \mathrm{m}^{-2}\right)\end{array}$} \\
\hline & & $0.6 \mathrm{~m}$ & $2 \mathrm{~m}$ & $10 \mathrm{~m}$ & $20 \mathrm{~m}$ & $40 \mathrm{~m}$ & $80 \mathrm{~m}$ & $140 \mathrm{~m}$ & $200 \mathrm{~m}$ & \\
\hline Jan & -0.17 & -0.20 & -0.17 & -0.13 & -0.11 & -0.09 & -0.07 & -0.07 & -0.03 & -9.1 \\
\hline Feb & -0.14 & -0.17 & -0.15 & -0.10 & -0.08 & -0.07 & -0.08 & -0.07 & -0.04 & -7.8 \\
\hline Mar & -0.17 & -0.21 & -0.16 & -0.09 & -0.07 & -0.05 & -0.03 & -0.03 & -0.04 & -4.0 \\
\hline Apr & -0.25 & -0.24 & -0.19 & -0.09 & -0.06 & -0.04 & -0.02 & -0.03 & -0.03 & -4.0 \\
\hline May & -0.25 & -0.23 & -0.20 & -0.11 & -0.09 & -0.06 & -0.04 & -0.03 & -0.04 & -5.3 \\
\hline Jun & -0.31 & -0.29 & -0.24 & -0.13 & -0.09 & -0.06 & -0.04 & -0.05 & -0.09 & -3.6 \\
\hline Jul & -0.40 & -0.31 & -0.27 & -0.12 & -0.09 & -0.06 & -0.06 & -0.08 & -0.08 & -6.2 \\
\hline Aug & -0.38 & -0.35 & -0.30 & -0.14 & -0.11 & -0.08 & -0.07 & -0.06 & -0.06 & -7.5 \\
\hline Sep & -0.32 & -0.30 & -0.24 & -0.12 & -0.09 & -0.07 & -0.06 & -0.06 & -0.05 & -6.6 \\
\hline Oct & -0.26 & -0.26 & -0.21 & -0.11 & -0.08 & -0.06 & -0.05 & -0.04 & -0.05 & -5.5 \\
\hline Nov & -0.22 & -0.23 & -0.18 & -0.10 & -0.08 & -0.06 & -0.05 & -0.06 & -0.06 & -5.0 \\
\hline Dec & -0.17 & -0.23 & -0.21 & -0.10 & -0.08 & -0.05 & -0.05 & -0.03 & -0.02 & -6.2 \\
\hline
\end{tabular}

The Cabauw observations were collected between 1986 and 1997 and were conditionally sampled according to the selection criteria presented in Table 1. The surface value indicates the tendency of the saturation specific humidity, which is computed from the radiative surface temperature. The column displaying $L_{v} E_{\text {budget }}$ gives the latent heat flux computed from the budget equation for the specific humidity (Eq. 12)

large-scale advection as much as possible, we here consider results from the dataset collected between 1986 and 1997 as it provides specific humidities at $0.6 \mathrm{~m}$. The results were bin-averaged; in addition, the standard deviation from the bin-mean of an arbitrary quantity $x$, 


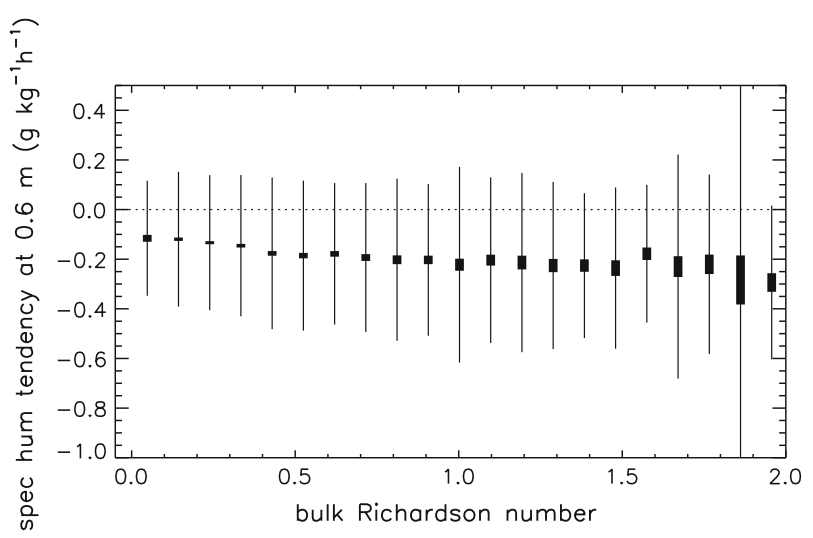

Fig. 4 The mean specific humidity tendency at $0.6 \mathrm{~m}$ height as a function of the bulk Richardson number. The thin vertical line represents the standard deviation, and the fat vertical line the uncertainty in the mean. The measurement points were sorted into 21 equidistant bins with a size of 0.095 . The results were computed from data that were collected from 1986 to 1997 and which satisfied the conditional sampling criteria I, II and III according to Table 1 . The parameter $R i_{B}$ was computed from the vertical gradients of $\theta_{v}$ and the mean horizontal wind speeds, and is representative of the stability at a height of $5 \mathrm{~m}$

$$
\sigma^{2}=\frac{\sum_{i=1}^{N_{b i n}}\left(x_{i}-\bar{x}\right)^{2}}{N_{b i n}}
$$

and the standard error in the mean, $\sigma_{m}=\sigma / \sqrt{N_{b i n}}$, with $N_{b i n}$ the number of data points used to compute the mean in a specific bin, were calculated.

Figure 4 displays the conditionally sampled humidity tendencies as a function of the bulk Richardson number. During the night longwave radiative cooling of the ground leads to a stable surface-layer stratification. If the wind speed becomes small, this leads to large values for $R i_{B}$, and as a result the buoyancy flux becomes negative acting to damp turbulent motions. Assuming a down-gradient flux and a turbulent Prandtl number of unity, turbulence will vanish if the vertical temperature stratification becomes very stable, i.e. if $R i_{B}>1$. However, it is found that drying occurs at $0.6-\mathrm{m}$ height even for relatively large values of $R i_{B}$. From a consideration of the vertical velocity equation, Zilitinkevich et al. (2007) argued that temperature fluctuations have the potential to generate vertical velocity fluctuations. As this argument holds for any value of $R i_{B}$, the drying trends could be explained by a heterogeneous temperature distribution inducing vertical motions.

The mean drying trend observed just above the surface at $0.6-\mathrm{m}$ height becomes larger for larger negative tendencies of $q_{s 0}$ (Fig. 5). The decrease of $q_{s 0}$ is due to a radiative cooling of the ground surface. Although this leads to a stronger vertical stability, a colder surface will lead to a larger potential for condensation of water vapour. In particular, if the temperature of the vegetation, or any other obstacle near the surface, falls below the dew point temperature of the ambient air, condensation will occur when a moist air parcel is in contact with such surface elements.

\section{Discussion}

In this section processes that can possibly explain the mean drying trends are discussed. In particular, large-scale advection of dry air and dew formation are considered. Also a bulk 


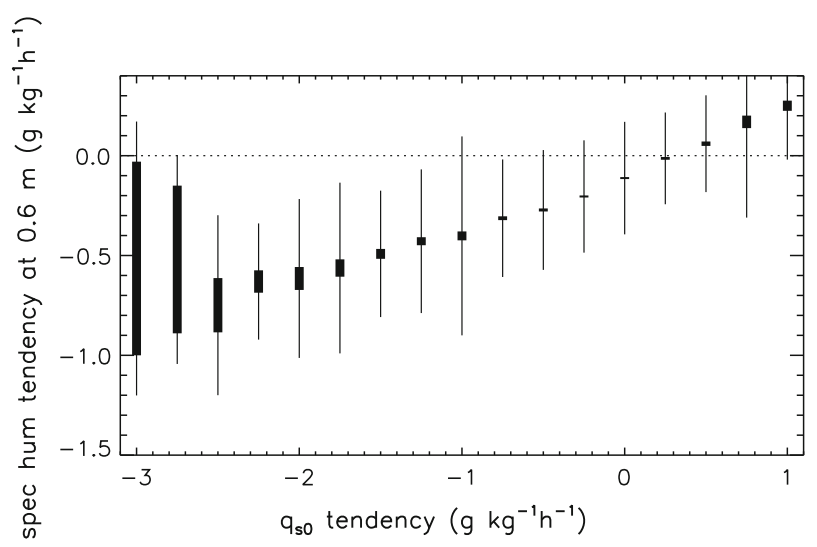

Fig. 5 The mean specific humidity at $0.6 \mathrm{~m}$ height as a function of the tendencies of the mean saturation specific humidity at the ground. The thin vertical line represents the standard deviation, and the fat vertical line the uncertainty in the mean. The measurement points were sorted into 21 equidistant bins with a size of $0.25 \mathrm{~g} \mathrm{~kg}^{-1} \mathrm{~h}^{-1}$. The results were computed from data that were collected from 1986 to 1997 and which satisfied the conditional sampling criteria I, II and III according to Table 1

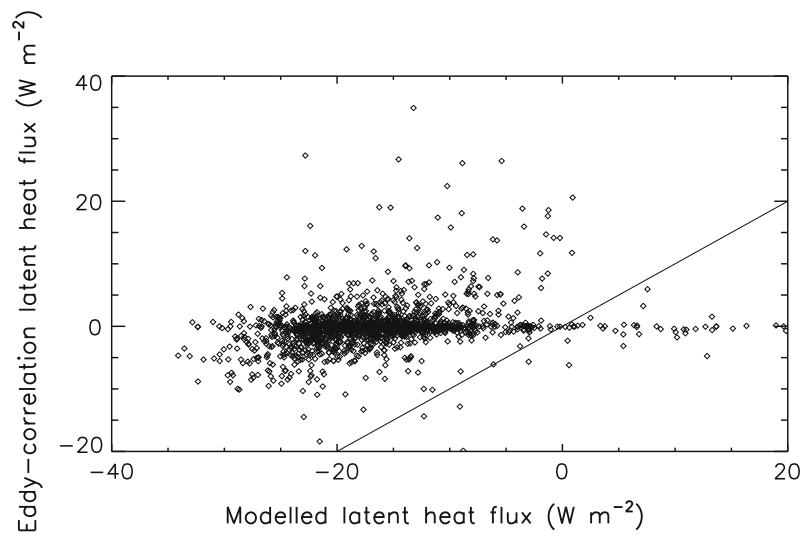

Fig. 6 Measured and modelled latent heat fluxes for clear nocturnal stable boundary layer conditions during the period 1994-1995. The line indicates $x=y$

estimation of the latent heat flux is calculated with the aid of the time series of the humidities measured from the tower and the budget equation for the humidity. Last, the latent heat fluxes obtained from the eddy-correlation technique are compared to results with a surface energy balance model (Fig. 6).

\subsection{Mean Advection}

Garratt and Segal (1988) suggested that mean horizontal advection can cause a significant local drying trend in the nocturnal boundary layer. An estimation can be made on the basis of the observed humidity tendencies at $200 \mathrm{~m}$, and the assumption that turbulent transport is negligibly small at this height. Clearly, Table 3 shows that the absolute values of the humidity tendencies are smaller than $0.1 \mathrm{~g} \mathrm{~kg}^{-1} \mathrm{~h}^{-1}$, which is much smaller than the tendencies observed close to the ground. 
The mean horizontal humidity gradient needed to explain the humidity tendencies can be estimated from

$$
\frac{\partial \bar{q}}{\partial x_{h}}=-\frac{1}{\overline{u_{h}}} \frac{\partial \bar{q}}{\partial t}
$$

where $x_{h}$ is the unit vector parallel to the mean wind direction. As an example, let $u_{h}=u_{\text {crit }}$, and the humidity tendency $-0.2 \mathrm{~g} \mathrm{~kg}^{-1} \mathrm{~h}^{-1}$, in which case $q$ needs to decrease by $1 \mathrm{~g} \mathrm{~kg}^{-1}$ over a horizontal distance of $50 \mathrm{~km}$ in the opposite direction of the mean wind vector. For smaller wind speeds, the horizontal gradient of $q$ must even be larger to cause an identical drying effect. To verify if a dominant wind direction can explain the mean drying trends, its probability distribution was computed for the conditionally sampled conditions. From this analysis it was found that a mean net drying is observed at 2-m height for any wind direction. If horizontal mean advection of dry air dominates the humidity budget, this should imply that the Cabauw tower area acts, on average, as a local sink of moisture. The fact that near the surface the drying is maximum and the mean horizontal wind speed is the smallest suggests that mean horizontal advection cannot explain the observed mean drying close to the ground.

The presence of ditches at the Cabauw site is a local source of evaporation that moistens the atmosphere. In particular during winter and autumn this phenomenon is often very visible with fog plumes rising upwards from the ditches. The rate of evaporation from the ditches is very difficult to quantify. In any case, as the net effect of the ditches is to moisten the atmosphere, larger drying trends can be expected in the absence of ditches.

The mean vertical velocity can be estimated from the mass continuity equation using $w=0$ at the ground,

$$
\bar{w}=-\left(\frac{\partial \bar{u}}{\partial x}+\frac{\partial \bar{v}}{\partial y}\right) z \equiv-D z
$$

where a typical value of the divergence $D$ during stable conditions is about $10^{-5} \mathrm{~s}^{-1}$, in which case the mean subsidence rate at $200-\mathrm{m}$ height will be $-2 \mathrm{~mm} \mathrm{~s}^{-1}$. If the mean vertical specific humidity gradient is $5 \mathrm{~g} \mathrm{~kg}^{-1} \mathrm{~km}^{-1}$, then the mean vertical advection term is $0.036 \mathrm{~g} \mathrm{~kg}^{-1} \mathrm{~h}^{-1}$ at this level. However, if turbulent convection during daytime has led to a vertically well-mixed structure of the specific humidity, smaller vertical gradients of $q$ can be expected. Because at the ground the subsidence must be zero, mean vertical advection of moisture by synoptic scale motions cannot explain the observed drying trends in the lowest few tens of metres. In the remainder of this study the contribution of the mean vertical advection to the humidity budget will be neglected, particularly as the mean subsidence rate cannot be measured.

\subsection{Latent Heat Fluxes Calculated from the Humidity Budget Equation}

The surface latent heat flux can be obtained from a vertical integration of the humidity budget equation, if it is assumed that the turbulent flux at $200-\mathrm{m}$ height is negligibly small during stable conditions. Furthermore it is assumed that the mean humidity advection increases linearly from zero at the ground surface to a value that is equal to the mean tendency observed at 200-m height. Using the humidity time series observed along the tower, the latent heat flux $L_{v} E_{\text {budget }}$ can be calculated from

$$
L_{v} E_{\text {budget }}=\left.\bar{\rho}_{\text {air }} L_{v} \overline{w^{\prime} q^{\prime}}\right|_{z=0}=\bar{\rho}_{\text {air }} L_{v} \int_{z=0}^{z_{\text {top }}}\left(\frac{\partial \bar{q}}{\partial t}(z)-\left.0.5 \frac{\partial \bar{q}}{\partial t}\right|_{z=200 \mathrm{~m}}\right) d z,
$$


Table 5 The total accumulated dewfall amount and the mean number of nights with dewfall per month in Wageningen, Netherlands, adapted from Figs. 5 and 7 presented by Jacobs et al. (2006)

\begin{tabular}{lllll}
\hline Month & $\begin{array}{l}\text { Mean total } \\
\text { (accumulated) dewfall } \\
\text { amount }(\mathrm{mm})\end{array}$ & $\begin{array}{l}\text { Mean number of } \\
\text { nights with dew }\end{array}$ & $\begin{array}{l}\text { Mean nighttime } \\
\text { hours }\end{array}$ & $\begin{array}{l}\text { Estimated } \\
\text { latent heat flux } \\
\left(\mathrm{W} \mathrm{m}^{-2}\right)\end{array}$ \\
\hline Jan & 3.2 & 20 & 15.9 & -7.4 \\
Feb & 2.8 & 17 & 14.4 & -8.2 \\
Mar & 3.0 & 19 & 12.5 & -9.3 \\
Apr & 3.0 & 22 & 10.5 & -9.4 \\
May & 2.8 & 20 & 8.6 & -11.6 \\
Jun & 2.7 & 21 & 7.6 & -12.0 \\
Jul & 2.5 & 22 & 8.0 & -10.1 \\
Aug & 3.1 & 25 & 9.7 & -9.4 \\
Sep & 3.3 & 24 & 11.6 & -8.4 \\
Oct & 3.7 & 13.6 & -8.7 \\
Nov & 3.5 & 23 & 15.4 & -7.7 \\
Dec & 3.1 & 21 & 16.4 & -6.7 \\
\hline
\end{tabular}

The last column shows the estimated latent heat flux for nights with dewfall. It is assumed that dewfall only takes place during nighttime. Copyright 2006 American Geophysical Union. Modified by permission of the American Geophysical Union

with $z_{\text {top }}=200 \mathrm{~m}$ being the maximum height of observation. The monthly mean surface latent heat fluxes computed in this way are presented in Table 3. The values are all negative, with the most negative values found during autumn, and are close to $-10 \mathrm{~W} \mathrm{~m}^{-2}$. Somewhat smaller values are found from the humidity tendencies obtained with aid of the wet-bulb temperatures (see Table 4). The latent heat fluxes as obtained from the humidity budget equation for both datasets give values that are at odds with the near-zero latent heat flux values obtained from the EC system.

The assumptions made in the estimation of $L_{v} E_{\text {budget }}$ cannot be verified from observations, neither are direct dewfall observations available to validate these results. However, a qualitative comparison can be made with results presented by Jacobs et al. (2006), who carried out direct dewfall measurements at the Wageningen University meteorological observatory, which is located about $50 \mathrm{~km}$ east of Cabauw. The observations were made in 2004 and were used to verify a surface energy dew model, which was subsequently applied to an 11-year dataset. Table 5 displays the monthly mean accumulated dew amounts, and the monthly mean number of nights with dewfall in Wageningen. These data were adapted from Figures 5 and 7 of Jacobs et al. (2006). The daily mean dewfall can be computed by dividing the monthly mean dewfall by the total mean number of days in a month with dewfall. The latent heat fluxes presented in Table 5 were obtained by assuming that dewfall occurs only during the full nighttime period. Furthermore, it was used that $1 \mathrm{~mm}$ dewfall per $24 \mathrm{~h}$ corresponds to a surface latent heat flux of about $-29 \mathrm{~W} \mathrm{~m}^{-2}$ (Garratt 1994). The dewfall data for Wageningen indicate a slight tendency for lower dew amounts during the longest daylight period (May to July), and vice versa during autumn. However, when taking into account that the nighttime period is much shorter for these months, the actual latent heat fluxes are maximum for the months May until July. Because the results presented herein are based on a rather small selection of data collected during stable conditions at Cabauw, a direct comparison between the Cabauw and Wageningen results cannot be made since the Wageningen dewfall data include any day with dewfall, irrespective of conditions. 


\subsection{Comparison to Modelling Results}

We applied the Penman-Monteith model for dewfall following Jacobs et al. (2006) for conditions that satisfied the sampling criteria for a clear nocturnal stable boundary layer during the period 1994-1995. To filter out the effect of large-scale advection the humidity tendencies observed at $80 \mathrm{~m}$ height were subtracted from the $2 \mathrm{~m}$ values. Integrated Monin-Obukhov stability functions were taken from Beljaars and Holtslag (1991). The boundary conditions were taken from observations of the net longwave radiation, the soil heat flux and the saturation deficit. A comparison of the modelled and the eddy-correlation fluxes as displayed in Fig. 6 shows a systematic underestimation of the measured latent heat flux.

\section{Conclusion}

Observations collected at the Cabauw meteorological measurement platform were conditionally sampled to select stable conditions with weak horizontal wind speeds and clear skies. For these conditions it is found that the residual in the surface energy balance is about $-30 \mathrm{~W} \mathrm{~m}^{-2}$, which is about half of the net longwave radiation at the ground surface. The eddy-correlation fluxes of moisture are negligibly small during these conditions. However, the observations show significant drying trends in the atmosphere, in particular close to the surface. The conditionally sampled monthly mean values for the latent heat flux were estimated from the time-height series of the humidity and the humidity budget equation. Negative values up to about $-10 \mathrm{~W} \mathrm{~m}^{-2}$ were found. These results, detailed dewfall observations collected $50 \mathrm{~km}$ east of Cabauw by Jacobs et al. (2006), and the application of their dewfall model to the Cabauw data suggest that some fraction of the residual in the surface energy balance can be explained by erroneously low latent heat fluxes as obtained from the eddy-correlation system.

It is remarkable that the drying trends in the lowest $2 \mathrm{~m}$ hardly depend on the stability as measured by the bulk Richardson number. This finding is particularly relevant to making accurate predictions of fog, as the transport of moisture to the ground during very stable conditions can be larger than would be expected on the basis of Monin-Obukhov theory.

The conclusion that water vapour transport during calm, clear-sky nighttime conditions is underestimated by the eddy-correlation method suggests that EC fluxes for other parameters, such as sensible heat, momentum and $\mathrm{CO}_{2}$, may be underestimated. In fact it is common practice to discard $\mathrm{CO}_{2}$ flux measurements when $u_{*}<0.1 \mathrm{~m} \mathrm{~s}^{-1}$ (Jacobs et al. 2008) and to use a respiration model instead to fill in the data gaps. Van de Wiel et al. (2003) concluded that the EC method yields turbulent heat fluxes that are systematically underestimated if the mean horizontal wind speed is small and turbulence very weak and intermittent. If turbulence is intermittent, observations of the vertical flux measured from a fixed location will yield a large random error.

Acknowledgements Reinder Ronda is kindly acknowledged for preparing the Cabauw dataset. Part of this research project was carried out in the framework the Dutch National Research Programme Climate changes Spatial Planning (http://www.klimaatvoorruimte.nl). We thank three anonymous reviewers for suggestions that helped to improve the manuscript.

Open Access This article is distributed under the terms of the Creative Commons Attribution Noncommercial License which permits any noncommercial use, distribution, and reproduction in any medium, provided the original author(s) and source are credited. 


\section{References}

Baas P, Bosveld FC, Baltink HK, Holtslag AAM (2009) A climatology of nocturnal low-level jets at Cabauw. J Appl Meteorol Clim 48:1627-1642

Beljaars ACM, Bosveld FC (1997) Cabauw data for the validation of land surface parametrization schemes. J Clim 10:1172-1193

Beljaars ACM, Holtslag AAM (1991) Flux parameterization over land surfaces for atmospheric models. J Appl Meteorol 30:327-341

Culf AD, Foken T, Gash JHC (2004) The energy balance closure problem. In: Kabat P, Claussen M, Dirmeyer PA et al (eds) Vegetation, water, humans and the climate; A new perspective on an interactive system. Springer Verlag, Berlin, pp 159-166

De Bruin HAR, Holtslag AAM (1982) A simple parametrization of the surface fluxes of sensible and latent heat during daytime compared with the Penman-Monteith concept. J Appl Meteorol 21:1610-1621

Foken T (2008) The energy balance closure problem: an overview. Ecol Appl 18:1351-1367

Foken T, Oncley SP (1995) Results of the workshop "Instrumental and methodical problems of land surface flux measurements”. Bull Am Meteorol Soc 76:1191-1193

Garratt JR (1994) The atmospheric boundary layer. Cambridge University Press, U.K., 316 pp

Garratt JR, Segal M (1988) On the contribution of atmospheric moisture to dew formation. Boundary-Layer Meteorol 45:209-236

Heusinkveld BG, Jacobs AFG, Holtslag AAM, Berkowicz SM (2004) Surface energy balance closure in an arid region: role of soil heat flux. Agric For Meteorol 122: 21-37. doi:10.1016/j.agrformet.2003.09.005

Holtslag AAM (2006) Preface: GEWEX atmospheric boundary-layer study (GABLS) on stable boundary layers. Boundary-Layer Meteorol 118:243-246

Holtslag AAM, de Bruin HAR (1988) Applied modelling of the nighttime surface energy balance over land. J Appl Meteorol 27:689-704

Jacobs AFG, Heusinkveld BG, Kruit RJW, Berkowicz SM (2006) Contribution of dew to the water budget of a grassland area in the Netherlands. Water Resour Res. doi:10.1029/2005WR004055

Jacobs AFG, Heusinkveld BG, Holtslag AAM (2008) Towards closing the surface energy budget of a midlatitude grassland. Boundary-Layer Meteorol 126:125-136

Kaimal JC, Wyngaard JC, Izumi Y, Cote OR (1972) Spectral characteristics of surface-layer turbulence. Q J R Meteorol Soc 98:563-589

Kohsiek W (2000) Water vapor cross-sensitivity of open path $\mathrm{H}_{2} \mathrm{O}-\mathrm{CO}_{2}$ sensors. J Atmos Ocean Technol 17:299-311

Kroon PS (2003) De sluiting van de oppervlakte energiebalans in Cabauw gedurende TEBEX (1995-1996). Technical report, Koninklijk Nederlands Meteorologisch Instituut, De Bilt, Netherlands, 68 pp

Kroon PS, Schuitmaker A, Jonker HJJ, Tummers MJ, Hensen A, Bosveld FC (2009) An evaluation by laser Doppler anemometry of the correction algorithm based on Kaimal co-spectra for high frequency losses of EC flux measurements of $\mathrm{CH}_{4}$ and $\mathrm{N}_{2} \mathrm{O}$. Agric For Meteorol. doi:10.1016/j.agrformet.2009.08.009

Stull RB (1988) An introduction to boundary layer meteorology. Kluwer Academic Publishers, Dordrecht, $666 \mathrm{pp}$

Van de Wiel BJH, Moene AF, Hartogensis OK, de Bruin HAR, Holtslag AAM (2003) Intermittent turbulence in the stable boundary layer over land: III. A classification for observations during CASES-99. J Atmos Sci 60:2509-2522

Van Ulden AP, Wieringa J (1996) Atmospheric boundary-layer research at Cabauw. Boundary-Layer Meteorol 78:39-69

Webb EK, Pearman GI, Leuning R (1980) Correction of flux measurements for density effects due to heat and water vapour transfer. Q J Roy Meteorol Soc 106:85-100

Zilitinkevich S, Elperin T, Kleeorin N, Rogachevskii I (2007) Energy- and flux-budget (EFB) turbulence closure model for stably stratified flows. Part I: steady state, homogeneous regimes. Boundary-Layer Meteorol 125:167-191 